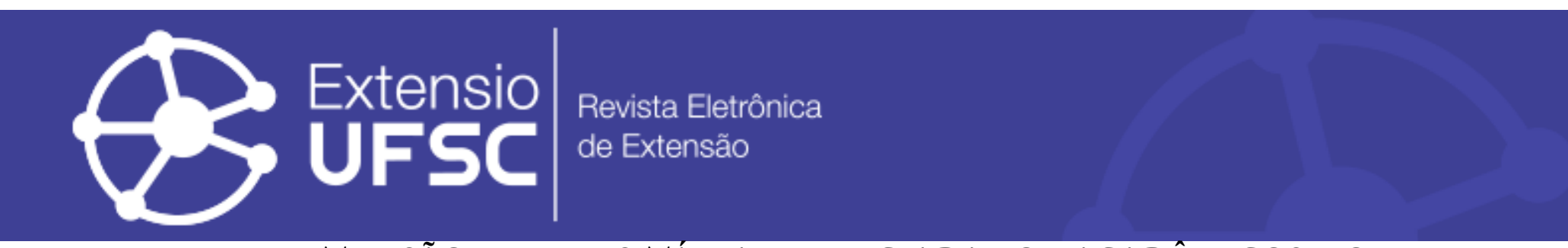

\title{
EXTENSÃO UNIVERSITÁRIA VIVENCIADA POR ACADÊMICOS NO PROJETO EDUCAÇÃO PARA TRANSFORMAÇÃO
}

Márcia Gilmara Marian Vieira

Universidade do Vale do Itajaí mmarian@univali.br

Ana Carolina Gelschleiter Borges Universidade do Vale do Itajaí ana-sjb@hotmail.com

Igor de Santana Sousa Bittencourt Universidade do Vale do Itajaí igorssousa1998@gmail.com

Resumo

O Projeto de Extensão tem como objetivo promover educação popular em saúde, meio ambiente para o desenvolvimento social, econômico e ambiental, estimulando assim, a participação cidadã como estratégia de mudança e autonomia. O presente relato, traz algumas experiências interdisciplinares vivenciadas pelos acadêmicos de Biologia. O principal objetivo foi possibilitar diferentes atividades como a saída de campo cuja finalidade primordial foi experienciar a interação entre ensino e extensão alusiva à agroecologia e à educação ambiental sustentável, essa complementa as atividades realizadas no I Seminário de Extensão Educação para Transformação. A metodologia do "Círculo de Cultura" foi priorizada para a problematização e para a reflexão da aprendizagem, realizou-se diversas iniciativas de promoção da agroecologia com o público alvo priorizando disseminar conhecimento através de oficinas de formação teóricas e práticas, grupo de estudos e seminários. Dessa forma, ressalta-se que esse se tornou uma realidade nas questões de meio ambiente e saúde.

Palavras-chave: Agricultura Sustentável. Meio Ambiente. Educação Ambiental.

\section{UNIVERSITY EXTENSION EXPERIENCED BY ACADEMICS IN EDUCATION FOR TRANSFORMATION PROJECT}

Abstract

The extension project aims to promote popular education in health, environment for social, economic and environmental development, stimulating citizen participation as a strategy for change and autonomy. The present report, portrays interdisciplinary experiences lived by academics. The principal objective was to enable different activities like a field trip which primordial purpose was to experience the interaction between education and extension allusive to agroecology and sustainable environmental education, this field trip complements realized activities in the I Extension Seminary of Education for Transformation. The methodology of the "Circle of Culture" was prioritized for the problematization and reflection of learning, which took place diverse initiatives of promotion of agroecology with the target public giving greater importance disseminate knowledge trough theoretical and practical formation workshops, study groups and seminaries. Therefore, it is noteworthy that this project has become a reality in issues of environment and health.

Keywords: Sustainable Agriculture. Environment. Environmental Education.

\section{EXTENSIÓN UNIVERSITARIA VIVENCIADA POR ACADÉMICOS EN EL PROYECTO EDUCACIÓN PARA TRANSFORMACIÓN}

\section{Resumen}

El Proyecto de Extensión tiene como objetivo promover educación popular en salud, medio ambiente para el desarrollo social, económico y ambiental, estimulando así la participación de la ciudadanía como estratégia de cambio y autonomía. El presente relato, trae algunas experiencias interdisciplinares vivenciadas por los académicos de Biología. El principal objetivo fue posibilitar diferentes actividades como la salida de campo cuya finalidad primordial fue experimentar la interacción entre enseñanza y extensión alusiva a la agroecología y a la educación ambiental sostenible, esa complementa las actividades realizadas en el I Seminario de Extensión Educación para la Transformación. La metodología del "Círculo de Cultura" fue priorizada para la problematización y para la reflexión del aprendizaje, se realizaron diversas iniciativas de promoción de la agroecología con el público objetivo priorizando diseminar conocimiento a través de talleres de formación teóricos y prácticas, grupo de estudios y seminarios. De esta forma, se resalta que ese se ha vuelto una realidad en las cuestiones de medio ambiente y salud.

Palavras clave: Agricultura Sostenible. Medio Ambiente. Educación Ambiental. 


\section{INTRODUÇÃO}

O Projeto de Extensão "Educação para a Transformação: meio ambiente, saúde e gênero", é vinculado à Universidade do Vale do Itajaí (UNIVALI), a qual pauta-se pelo tripé: ensino, pesquisa e extensão e, nesta última área, desenvolve vários projetos em consonância com o contexto social, político e econômico. Segundo Santos (2012, p. 155), a extensão configura-se em uma das formas de atuação mais necessárias, pois a Universidade é uma realidade social e política; uma Instituição Educacional que expressa a sociedade da qual faz parte.

Esta proposta é tema-alvo de interesse, de investigação e de atuação dos docentes e discentes dos cursos de graduação de Ciências Biológicas, Engenharia Ambiental, Nutrição, Administração, Ciências Contábeis e de Enfermagem da UNIVALI, visto que os Parâmetros Curriculares Nacionais (PCNs) instituem os temas transversais. Segundo o Ministério da Educação (MEC), os temas como meio ambiente, saúde e pluralidade cultural devem estar voltados para a compreensão e para a construção da realidade social e dos direitos relacionados com a vida pessoal e coletiva, bem como, com a afirmação do princípio de participação política (ARAÚJO, 2009).

Este é o relato da experiência vivenciada no Projeto de Extensão que tem como objetivo promover educação popular em saúde, meio ambiente, e relações de gênero para o desenvolvimento social, econômico e ambiental, estimulando a participação cidadã como estratégia de mudança e autonomia. Além disso, o Projeto incentiva a soberania das mulheres agricultoras de Itajaí-SC e os acadêmicos do curso de Ciências Biológicas a buscar respostas frente às questões ambientais e de sustentabilidade, promovendo o empoderamento e a liberdade para a transformação de seu território, considerando que, essas pessoas podem ser multiplicadoras na disseminação de informação e conhecimento.

Essa proposta implica o encontro de sujeitos para refletirem sobre sua realidade concreta, a fim de denunciar situações conflitantes e anunciar ações que venham a intervir neste contexto, assim, Freire (1983), denomina esse encontro de saberes como Círculo de Cultura. A problematização permite ao sujeito se distanciar de sua experiência imediata e, em diálogo crítico com o outro, transcender a consciência ingênua, construindo sentidos para sua ação. Por outro lado, a dialogicidade pressupõe relações de reciprocidade, com as quais os sujeitos educativos trocam experiências, saberes, e também necessidades do cotidiano profissional e existencial.

A saída de campo representa conhecer um espaço que significa muito mais que um lugar de visita, já que, mediante o contato direto com a natureza, o aluno pode aprender toda a dinâmica do ecossistema que está estudando, e isso lhe permitirá discutir com segurança acerca 


\section{Extensão Universitária vivenciada por acadêmicos no projeto Educação para Transformação}

dessas questões e também sugerir formas alternativas e ambientalmente sustentáveis para a sua realidade, no momento em que tiver a oportunidade de se manifestar (CAMPOS, 2012, p.26). Assim sendo, constata-se que a experiência da saída de campo contribuirá para a formação do indivíduo que logo se tornará um profissional.

É necessário, conforme aduz Freire, despertar a curiosidade epistemológica a partir de uma aprendizagem significativa. Assim como cada pessoa, compreendida a partir de sua individualidade, é única, assim também o é, cada espaço não formal. A saída de campo busca, pois, permitir que o aluno compreenda essa característica, isto é, que a natureza é diferente, pois sobre ela e, a partir dela, move-se a ação humana. Por intermédio de um olhar crítico sobre a natureza, o aluno poderá compreender os conceitos teóricos de modo dialético, e não de modo passivo. As saídas de campo precisam, portanto, de um planejamento que compreenda o précampo, o campo e o pós-campo. Cada uma dessas fases contém objetivos distintos, os quais tentarão colaborar para a busca de uma educação mais democrática e prazerosa (SILVA, SILVA e VAREJÃO, 2010).

As atividades de campo constituem importante estratégia para a formação profissional, uma vez que permitem explorar uma grande diversidade de conteúdo, motivar os estudantes, a fim de possibilitar o contato direto com o ambiente e a melhor compreensão dos fenômenos. Para tanto, é imprescindível que essas sejam bem preparadas e adequadamente exploradas. Além disso, é importante que os professores trabalhem juntos e explorem as atividades de campo, de forma interdisciplinar, permitindo superar entraves, com o objetivo de torná-las mais frequentes e melhor utilizadas no meio acadêmico (DINIZ; VIVERO, 2009).

É importante salientar que o ensino interdisciplinar no campo ambiental deve focar o "estudo das relações entre processos naturais e sociais, dependendo da capacidade das ciências para articular-se, oferecendo uma visão integradora da realidade" (LEFF, 2001, p. 228). Nessa perspectiva, a interdisciplinaridade, "se traduz como um trabalho coletivo que envolve conteúdos, disciplinas e a própria organização" (LOUREIRO, 2004, p. 76).

A saída de campo foi organizada, não só para promover a autonomia e a autorregulação do acadêmico relativamente às aprendizagens pretendidas, como também para propiciar o trabalho colaborativo e a busca de soluções para as questões que surgiram durante essa experiência. O principal objetivo desse relato foi possibilitar diferentes atividades como a saída de campo cuja finalidade primordial foi experienciar a interação entre ensino e extensão alusiva à agroecologia e à educação ambiental sustentável, essa complementa as atividades realizadas no I Seminário de Extensão Educação para Transformação. 
Extensão Universitária vivenciada por acadêmicos no projeto Educação para Transformação

\section{METODOLOGIA}

No início do segundo semestre de 2016, algumas oficinas foram programadas pela equipe extensionista, a fim de que os acadêmicos, de diferentes períodos, do curso de Ciências Biológicas e também as mulheres agricultoras pudessem vivenciar experiências relacionadas às questões ambientais e de sustentabilidade. Uma das propostas inseridas para os estudantes foi a saída de campo interdisciplinar, que ocorreu após reflexões e problematizações no espaço da sala de aula e em práticas experimentais, oferecidas em oficinas organizadas pela equipe do Projeto, incluindo temáticas como: agricultura convencional x agricultura alternativa; o processo de transição para uma agricultura sustentável, bem como o desenvolvimento de atitudes como senso de responsabilidade ambiental, desenvolvimento sustentável, social e o trabalho coletivo.

Essa saída de campo complementa as atividades realizadas no I Seminário de Extensão Educação para Transformação, as quais visavam à interação do ensino e extensão alusiva à Agroecologia e à Educação Ambiental Sustentável, bem como à realização da "Horta Orgânica Experimental" em conjunto com os Acadêmicos de Biologia.

A Metodologia empregada nas atividades do Projeto de Extensão teve em seu bojo ações educativas, consoante as propostas pedagógicas de Educação, na perspectiva de Paulo Freire. Durante todas as atividades realizadas, foi priorizado o "Círculo de Cultura" para a "problematização e a dialogicidade" seguido da reflexão para a concretização da aprendizagem.

No dia 26 de julho de 2016, realizou-se a saída de campo interdisciplinar relacionada ao Projeto de Extensão Educação para a Transformação: meio ambiente, saúde e gênero, que aconteceu no Espaço Ambiental Gaia Village, em Garopaba-SC, juntamente com os acadêmicos e professores das disciplinas de Química Geral ( $1^{\circ}$ período), Química Orgânica (2 período), Ecologia Fundamental ( $1^{\circ}$ período) do curso de Ciências Biológicas da UNIVALI. Participaram sessenta e cinco acadêmicos, distribuídos entre: acadêmicos viventes (59), acadêmicos facilitadores (2), e professores (04).

O Projeto Gaia, localizado na Praia do Ouvidor, no município de Garopaba/SC, tem esse nome inspirado na ideia de natureza integrada, conforme verifica-se abaixo, na figura 1.

$\mathrm{Na}$ chegada ao Espaço, uma das colaboradoras do Projeto (Bióloga responsável), organizou uma roda de conversa para apresentar aos participantes o trabalho realizado pelo Projeto Gaia. Inicialmente, aquele local era utilizado como casa de veraneio da família Werlang, de forma que seus filhos pudessem vivenciar o contato direto com a natureza; mas, com o passar dos anos, inspirado no modelo de algumas comunidades européias e movido pelo desejo de 
preservar aquele espaço e desenvolver e aplicar uma forma de vida sustentável e harmoniosa, foi criado o Projeto Gaia, sob os ensinamentos do ambientalista José Lutzenberger.

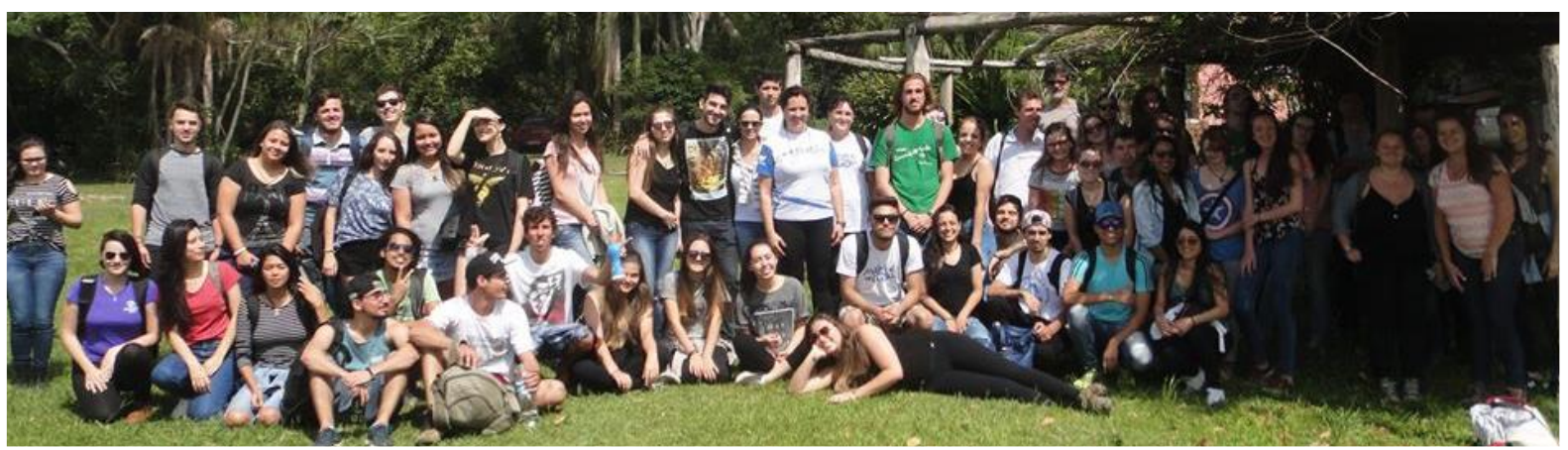

Figura 1. Participantes da saída de campo ao Espaço Ambiental Gaia Village.

Na sequência, a Bióloga apresentou também os diversos Programas desenvolvidas pelo Projeto, quais sejam: 1. Programa de Preservação e Recuperação de Ecossistemas; 2. Programa de Produção Rural e Sustentável; 3. Programa de Tecnologias Ambientalmente Amigáveis; 4. Programa de Infraestrutura de Edificações; 5. Programa de Desenvolvimento Humano; 6. Programa de Sensibilização e Educação Ambiental e, 7. Programa de Saúde Sustentável.

No segundo momento, o grupo foi direcionado ao Espaço Eco Garopaba, local em que foi possível observar o processo de reciclagem de garrafas PET, para a produção de pranchas de surf e stand-up, como forma de incentivar o esporte, e de verificar a importância de preservar o meio ambiente, tal como de reciclar os materiais reutilizáveis.

No terceiro momento, o grupo foi para a sede do Espaço Gaia, onde seguiram uma trilha de $4 \mathrm{~km}$ até a Praia do Ouvidor. Durante o percurso, os acadêmicos puderam observar todos os projetos apresentados, bem como a importância de se preservar o ambiente e a sustentabilidade do espaço.

Ao finalizar a saída de campo, os alunos se dirigiram à casa sede, na Praia do Ouvidor, presenciando nesse espaço as diversas maneiras de Sustentabilidade, sendo elas: a compostagem de resíduos orgânicos, os banheiros secos, a energia solar e a energia eólica, a recuperação e a reestabilização dos solos, assim como o reaproveitamento da água da chuva em um único espaço. Em seguida, desfrutaram de um café com alimentos orgânicos, cultivados na propriedade. 


\section{RESULTADOS E ANÁLISES}

No início do semestre de 2016 foi apresentado o Projeto de Extensão Educação para Transformação, os seus objetivos e as suas diretrizes, como também foi entregue aos acadêmicos um Cronograma das atividades a serem desenvolvidas. Sugestões de referências bibliográficas e um roteiro para a implementação do processo de aprendizagem, também foram sugeridos, bem como os seguintes documentários: A História das Coisas; Brasil Orgânico e O Veneno está na mesa II e, ainda, a leitura do livro Projeto Vida no Campo: A vida em harmonia com a natureza. Disponível

em: http:www.projetovidanocampo.com.br/downloads/Projeto_Vida_no_Campo_(Livro).pdf ). Salienta-se que, a intenção inicial da professora moderadora era introduzir os acadêmicos nas discussões e problematizações sobre as temáticas de interesse do Projeto de Extensão.

Dando continuidade, os acadêmicos foram convidados a participar do I Seminário de Extensão Educação para Transformação: meio ambiente e saúde, realizado no dia 16 de agosto de 2016, nas dependências da UNIVALI, e organizado pela equipe extensionista, momento em que tiveram a oportunidade de acompanhar muitas palestras, cujos temas versaram sobre: AGROTÓXICOS E OS IMPACTOS NO MEIO AMBIENTE E NA SAÚDE bem como as possibilidades de uma AGRICULTURA SUSTENTÁVEL COMO A AGROECOLOGIA.

Nesse momento, os estudantes ficaram muito sensibilizados com os conhecimentos e com a troca de saberes adquiridos no Seminário e, como futuros profissionais da Biologia, ficaram ansiosos e mobilizados para começar a fazer a sua parte como cidadãos. A seguir, os acadêmicos e extensionistas participaram de uma roda de conversa para levantar os temas geradores dessa vivência e foram motivados à implantação da "HORTA ORGÂNICA EXPERIMENTAL DO PROJETO DE EXTENSÃO”, dentro das dependências da UNIVALI.

No final do semestre, para ampliar o ciclo de conhecimentos e o fortalecimento do grupo, aconteceu a saída de campo interdisciplinar no Espaço Ambiental Gaia Village, local em que os participantes puderam vivenciar diversas ações consolidadas durante muitos anos e que são exemplos de sustentabilidade e cuidados com o ser humano e o ambiente.

As saídas de campo constituem importante estratégia para o ensino, uma vez que permitem explorar uma grande diversidade de temáticas que motivam os estudantes, possibilitando, assim, o contato direto com o ambiente e a melhor compreensão dos fenômenos.

A diversificação de atividades e de recursos didáticos contribuiu para fomentar os acadêmicos, oportunizando atender a distintas necessidades e interesses, sendo fundamental para que tenham uma aprendizagem significativa e percebam que não há um único caminho que 
conduza, com segurança, à aprendizagem, e sim, que são inúmeras as variáveis que se interpõem nesse processo.

Após a saída de campo, foi sugerido, como uma estratégia de avaliação, que os acadêmicos elaborassem um relato da experiência vivenciada durante o semestre, confirmando essa proposta de trabalho. Exemplo disso, traz-se a fala de uma aluna de Química Orgânica, que pontua:

"A saída de campo foi uma experiência valorosa e condizente com tudo aquilo
que tanto trabalhamos durante o semestre no curso de Ciências Biológicas, e a
possibilidade de presenciar a realização de um Projeto tão maravilhoso que nos
dá esperança de um mundo melhor, além da vontade de cada vez mais
contribuir com o desenvolvimento sustentável."

Durante a roda de conversa e as visitas ao Espaço Ambiental Gaia, os acadêmicos tiveram a possibilidade de conhecer o banheiro seco como alternativa sustentável, ressaltando a necessidade de um cuidado maior com a água do mundo.

Inicialmente, essa proposta do banheiro seco gerou certa resistência entre alguns acadêmicos quanto à higiene e à limpeza integral do ambiente, contudo, depois das explicações dadas sobre a importância para o ambiente e a eficácia na contenção dos odores, principalmente àqueles associados à preservação da água, evitando a contaminação dos lençóis freáticos e o resíduo compostado sendo reutilizado, isso fez com que as pessoas valorizassem essa possibilidade.

Outra aluna, expressa o seu pensar, dizendo:

"Desde o início do semestre fiquei ansiosa para essa saída de campo, eu sabia que seria uma experiência única. Depois de assistirmos à apresentação do projeto fiquei raciocinando todas as informações e percebi como é necessário o reaproveitamento da matéria orgânica por meio das compostagens, pois é um meio muito simples de reduzir o desperdício. Pensei muito também em relação aos banheiros secos, pois é a melhor forma de evitar a poluição dos mares e o desperdício da água potável, porém, extremamente trabalhoso e necessita de tempo para a manutenção, fora isso achei muito conveniente para pessoas que têm espaço em casa para a infraestrutura do banheiro e tempo para os devidos cuidados."

Já, outro acadêmico ressalta que:

"Mostrou-se extremamente necessária e de vital importância toda a experiência vivida durante o andamento do cronograma planejado pelos docentes das disciplinas de Química Geral, Química Orgânica e Ecologia Fundamental, proporcionando aos acadêmicos a possibilidade de percepção analítica a respeito das teias biológicas dos sistemas agregados entre si e da reciclagem de matéria orgânica na qual o fluxo de energia torna-se constantemente delicado, sendo assaz prejudicado, necessitando assim, de um cuidado vigente maior, onde o índice de impactos sobre esse ambiente seja diminuto, visando ao menor dano possível para a fauna e a flora ambiental." 
Ele continua, destacando que:

"De modo geral, após a roda de conversa, os alunos foram apresentados a ideias ecossustentáveis como, por exemplo, a construção e o aproveitamento de banheiros secos, fiquei um pouco assustado no início dessa apresentação, mas depois fui realmente verificar como funcionava e mudei o modo de pensar, outra proposta foi à das PANCS (Produtos alimentícios não-convencionais) e o uso de uma agricultura livre de agrotóxicos que torna o alimento saudável e livre de venenos."

Também foram apresentados aos participantes o painel solar gerador de energia limpa e sustentável como importante ferramenta para a preservação ambiental, otimizando boa parte (em média de 70\%) da utilização de energia elétrica na sede do espaço.

Outra ideia inovadora apresentada foi a confecção de pranchas e stand-up, utilizando material reciclável, em especial, garrafas PET. Essa iniciativa, realizada no espaço Eco Garopaba, mostrou-se uma saída extremamente sustentável, agregando não apenas a questão ecológica como também a promoção de esportes com uma consciência ambiental. A confecção de pranchas de surf e stand-up com o uso de material reciclável para a prática de atividades esportivas foi desenvolvida por um praticante dos esportes, mostrando a reciclagem como forma de sustentabilidade.

Dois alunos do curso de Biomedicina, que também participaram das atividades, falaram o seguinte sobre essas experiências:

"Participar dessa saída de campo com toda a certeza nos fez evoluir e refletir sobre nossos atos e nos impactou mais do que esperávamos, nós como biomédicos damos mais atenção à saúde em nossa profissão, de fato é o nosso foco, mas conseguimos perceber que protegendo o meio ambiente é uma forma indireta de proteger a saúde também, principalmente na produção de alimento orgânico, já que temos grande conhecimento sobre os danos causados pelos venenos chamados de agrotóxicos. Unir nossos conhecimentos nos fez ter uma perspectiva maior sobre a relação entre homem e natureza, e isso contribuirá, significativamente, em nossa profissão. Somos gratos por podermos ter tido essa experiência, pois olhando somente de um ponto de vista jamais iríamos ter noção da importância e da necessidade que há, de que cada um deve fazer sua parte."

Para finalizar, cumpre destacar a fala de mais um dos acadêmicos:

"A saída de campo foi de grande engrandecimento, tanto em conhecimento, pois aprendemos formas alternativas para buscar ter uma vida que não degrade, ou que minimize o máximo de impactos no meio ambiente, como também espiritualmente, renovando nossa força e nosso desejo de sermos competentes, procurando viver em completa harmonia com o meio ambiente, pois essa é uma das nossas principais funções como cidadãos e futuros Biólogos."

Os acadêmicos tiveram a possibilidade de vivenciar uma realidade com a qual o ser humano está integrado, ou seja, o meio ambiente, mas não de forma contrária, isto é, a 
contradição global de que a espécie humana, além de ser superior e complexamente localizada no topo da cadeia evolutiva, deve viver da natureza sem o respeito e a auto-inserção no ambiente.

O surgimento de iniciativas que buscam cuidar da natureza é uma resposta a uma série de problemas existentes no mundo, destacando-se: desmatamento de florestas e mata atlântica, poluição das cidades, do ar e de recursos hídricos, como rios, lagos, lagoas e oceanos, além de atividades como a caça e a pesca predatória. Para reduzir os danos causados pelos crimes ao meio ambiente, uma atitude simples, para que cada um possa fazer a sua parte, é adquirir hábitos sustentáveis simples e eficientes.

Por se tratar de um espaço preservado e que sedia um Projeto com tantos exemplos práticos de desenvolvimento sustentável, o local escolhido para a realização desta saída de campo foi condizente com os objetivos do Projeto de Extensão da UNIVALI. Nesse sentido, é amplamente discutida a necessidade de uma mudança de atitude em relação ao meio ambiente e à saúde, porque tudo aquilo que é vivenciado, de maneira concreta, produz impacto maior e mais duradouro, apresentando, com isso, a maior integração entre o homem e o meio ambiente, promovendo educação ambiental, momentos de paz e aconchego. Fazendo isso, o indivíduo poderá buscar o contato com sua natureza interior, a fim de alcançar o contato com o seu exterior.

Com estas ações, o projeto visa ampliar as fronteiras entre a universidade e a comunidade, trazendo soluções diárias para a vida da população, fortalecendo estes elos entre a teoria científica e a aplicação das práticas, visando um meio ambiente mais sustentável por meio da agroecologia.

\section{CONSIDERAÇÕES FINAIS}

No decorrer do Evento, percebeu-se que as atividades de extensão que foram oportunizadas por meio do projeto Educação para Transformação: meio ambiente, saúde e gênero, estimularam os acadêmicos do curso de Ciências Biológicas, por meio da vivência de novas experiências interdisciplinares, as quais proporcionam o aprimoramento dos conhecimentos técnicos e ambientais. Esses futuros profissionais precisam estar bem preparados para compreender que os agroecossistemas estão em constante evolução com os sistemas sociais e biológicos.

Portanto, a saída de campo realizada, promoveu conhecimentos sobre diferentes práticas sustentáveis e, principalmente, despertou nos acadêmicos uma visão sobre os prejuízos causados pelos agrotóxicos, como também os impactos ao meio ambiente e à saúde. Além disso, promoveu iniciativas para a implementação da "Horta Orgânica Experimental". 
Com todas essas possibilidades, os acadêmicos tiveram a oportunidade de trocar saberes, os quais foram consolidados com ações que são exemplos de sustentabilidade e cuidado com o ser humano e com o meio ambiente.

Diante disso, é mister reconhecer que os agricultores e suas famílias detêm um saber que é tão importante quanto os nossos saberes. Portanto, nossa ação deve ser capaz de integrar esses diferentes saberes, a fim de buscar a construção social de conhecimentos para promover a gestão dos agroecossistemas, tendo como elemento norteador o desenvolvimento sustentável das comunidades. É necessário, ainda, formar profissionais que promovam o desenvolvimento sustentável, contemplando o interesse local e comunitário, orientados pelo imperativo sócio ambiental.

\section{REFERÊNCIAS}

ALGUMAS MANEIRAS EFICIENTES PARA PRESERVAR O MEIO AMBIENTE. 2014. Disponível em: <http://www.atitudessustentaveis.com.br/artigos/algumas-maneiras-eficientespreservar-meio-ambiente/>. Acesso em: 05 dez. 2016.

ARAÚJO, Ricardo Afonso Pereira de. Relações entre o tema transversal meio ambiente e a questão da sustentabilidade do turismo aplicada ao ensino fundamental do distrito federal. 2009. 96 f. Monografia (Especialização em Formação de Professores na área de turismo), Universidade de Brasília, Brasília, 2009.

CAMPOS, C. R. P. A saída a campo como estratégia de ensino de ciências. Revista Eletrônica Sala de Aula em Foco, v.1, n.2, p. 25-30, 2012.

DINIZ, A. A.; VIVEIRO, R. E. da S. Atividades de Campo no Ensino das ciências e na educação ambiental: refletindo sobre as potencialidades desta estratégia na prática escolar. São Paulo. UNESP In: Ciência em Tela - v. 2, n.1, 2009.

FREIRE, P. Reglus Neves. Pedagogia do oprimido. Rio de Janeiro: Paz e Terra, 1983.

LEFF, E. Saber Ambiental: sustentabilidade, racionalidade, complexidade, poder. Petrópolis: Vozes, 2001.

LOUREIRO, C. F. B. Trajetória e fundamentos da educação ambiental. São Paulo: Cortez, 2004.

SANTOS, Marcos Pereira dos. Extensão Universitária. Espaço de aprendizagem profissional e suas relações com o ensino e a pesquisa na educação superior. Rev. Conexão UEPG. Ponta Grossa, v.8, n.2, jul./dez., 2012, p. 154-163. 
Extensão Universitária vivenciada por acadêmicos no projeto Educação para Transformação

SILVA, J. S. R.; SILVA, M. B.; VAREJÃO, J. L. Os (dez) caminhos da educação: a importância do trabalho de campo na Geografia. VÉRTICES, Campos dos Goytacazes/RJ, v. 12, n. 3, p. 187-197, set/dez. 2010.

Recebido em: 15/12/2016

Aceito em: 18/06/2018 